\title{
Can Nutrition Lower the Risk of Recurrence in Breast Cancer?
}

\author{
Julia Weigl Hans Hauner Dagmar Hauner
}

Institute for Nutritional Medicine, Else Kröner-Fresenius-Center for Nutritional Medicine, University Hospital Klinikum rechts der Isar, Technical University of Munich, Munich, Germany

\section{Keywords}

Breast cancer - Diet - Dietary pattern - Recurrence . Mortality

\section{Summary}

Background: The impact of diet on breast cancer prognosis is poorly understood. Therefore, we conducted a literature search summarizing the current evidence on the effect of diet on breast cancer recurrence and mortality. Methods: The PubMed database was searched for original studies, reviews, and meta-analyses published between 2010 and 2017. Studies related to diet, dietary patterns, special diets or specific dietary factors, and breast cancer recurrence or mortality were included. Results: Adherence to high diet quality indices (relative risk (RR) 0.74 , 95\% confidence interval (Cl) $0.60-0.90$ ) and a prudent/healthy dietary pattern (RR $0.76,95 \% \mathrm{Cl} 0.60$ 0.95) may have a beneficial effect on breast cancer prognosis, whereas a Western/unhealthy diet is associated with poorer overall mortality (RR 1.44, 95\% Cl 1.17-1.77). For low-fat diets, the findings are inconsistent. A positive effect of the Mediterranean Diet was found for all-cause mortality, but no beneficial effect from other diets such as low-carbohydrate, ketogenic or vegetarian/vegan diets was observed. Alcohol consumption was associated with an increased risk for breast cancer recurrence. No general recommendation for soy exists, but occasional intake seems to be acceptable, whereas the use of other supplements is not justified. Conclusion: Adherence to high-quality diets and a prudent/healthy dietary pattern seem to be beneficial for breast cancer prognosis. No clear evidence for a benefit from special diets, soy products, or other supplements was found.

(C) 2018 S. Karger GmbH, Freiburg

\section{Introduction}

Breast cancer is the most common cancer in women with about 71,000 newly diagnosed cases and roughly 18,000 deaths every year in Germany [1]. Given the high 5-year survival rate of currently $88 \%$ [1], it becomes more and more important to examine which lifestyle factors could have a protective effect on breast cancer outcome. Many studies have already evaluated the role of such factors on breast cancer prognosis, including diet [2-5], obesity/overweight [6-9], physical activity [10-13], smoking [14, 15], and breastfeeding [16]. The strongest evidence for an effect on breast cancer outcome was found for obesity/overweight and physical activity $[7,12]$. In contrast, the association between diet or specific dietary components and breast cancer prognosis is weak and inconsistent. However, there are trends that dietary fat appears to increase mortality, whereas diets high in fiber may be protective [6]. A recent review summarized that a prudent/healthy diet rich in fruit, vegetables, wholegrain products, legumes, poultry, and fish seems to have a beneficial effect on all-cause mortality in breast cancer survivors. In contrast, a Western/unhealthy diet characterized by a high intake of refined grains, red meat, processed meat, and high-fat dairy products was linked to increased non-breast cancer-specific mortality and was significantly associated with increased all-cause mortality [17].

The aim of this article is to present an overview of the latest published research on diet, dietary patterns, special diets, and specific dietary factors related to breast cancer survival and recurrence.

\section{Material and Methods}

We searched PubMed to identify relevant studies, systematic reviews, and meta-analyses which were published between 2010 and 2017. The search terms applied were 'Diet AND breast cancer recurrence' as well as 'Diet AND breast

\section{KARGER \\ Fax +497614520714

() 2018 S. Karger GmbH, Freiburg 
cancer mortality'. Similarly, we combined the term 'Dietary pattern' and special diets as 'Ketogenic diet', 'Low carbohydrate diet', 'Mediterranean diet', and 'Vegetarian diet'. We also added relevant studies, reviews, and meta-analyses concerning frequently discussed dietary factors like 'Soy' and 'Vitamin D'. In addition, the report of the World Cancer Research Fund (WCRF) on the role of lifestyle factors in breast cancer survivors was included [18].

\section{Results}

\section{Diet}

Up to now, there is only a limited number of randomized intervention trials to be found which have investigated the influence of diet on breast cancer prognosis. Two large studies, the Women's Intervention Nutrition Study (WINS) [19] and the Women's Healthy Eating and Living (WHEL) study [20], addressed the question whether a reduction of fat intake to $15-20 \%$ of total energy and for WHEL an additional high intake in vegetables, fruit, and grains - improves the prognosis of early-stage breast cancer survivors $[19,20]$. Neither study reported an intervention effect on overall survival (WINS: hazard ratio (HR) $0.89,95 \%$ confidence interval (CI) 0.65-1.21, p = 0.56; WHEL: adjusted HR 0.91, 95\% CI $0.72-1.15, \mathrm{p}=0.43$ ). Regarding the primary endpoint disease-free survival, the WHEL study did not achieve statistical significance (adjusted HR 0.96, 95\% CI 0.80-1.14, p = 0.63) [20], whereas for the WIN study a favorable effect of the dietary intervention was observed with marginal significance (HR 0.76, 95\% CI 0.60-0.98, p $=0.077$ for the stratified log rank test, $\mathrm{p}=0.034$ for the adjusted Cox model) [19]. A possible explanation for these differing results can be found in the difference in weight development. In contrast to WHEL, WINS showed a modest but statistically significant weight loss in the women of the intervention group (weight difference compared to the control group $=2.7 \mathrm{~kg}, \mathrm{p}=0.005$ ) [19] When interpreting the results of both studies, it should be noted that the intervention programs did not consider fat quality, many other dietary factors, or any other potentially relevant lifestyle factors.

\section{Role of Dietary Patterns}

The analysis of dietary patterns is an upcoming approach in the studies on the role of diet for breast cancer outcome and investigates the effect of diet in total. In an analysis of participants with breast cancer from the Nurses' Health Study (NHS), both the prudent and Western dietary pattern was unrelated to all-cause or breast cancer mortality [21]. In a subsequent study in 2,729 women with invasive stage 1-3 breast cancer, again from the NHS, no association was found between 4 dietary quality scores and breast cancer-related death [22].

In another cohort study from the Kaiser Permanente Northern California Cancer Registry including 1,901 women with early breast cancer, neither a prudent nor a Western dietary pattern was associated with risk of breast cancer recurrence or death from breast cancer [23].

In a more recent analysis of women diagnosed with breast cancer from the NHS, high diet quality scores, based on the Dietary
Approaches to Stop Hypertension (DASH) score and the Alternative Healthy Eating Index-2010, were not associated with breast cancer recurrence and mortality [24]. In a prospective follow-up of 2,522 German women with postmenopausal breast cancer, a healthy dietary pattern was inversely associated with overall mortality (HR 0.74, 95\% CI 0.47-1.15, p-trend 0.02) and breast cancer recurrence (HR 0.71, 95\% CI 0.48-1.06, p-trend 0.02) in stage IIIIa patients only. No associations with breast cancer-specific mortality and recurrence were reported for an unhealthy dietary pattern [25].

In breast cancer survivors (41 cohort studies), a recently published systematic review and meta-analysis [26] showed an association of decreased overall mortality and adherence to high diet quality indices (high intake of fruit, vegetables, whole grains, legumes, and nuts as well as low intake of red and processed meat) (RR 0.74, 95\% CI 0.60-0.90, 3 studies) and adherence to a prudent/healthy dietary pattern (high intake of fruit, vegetables, whole grains, poultry, and low-fat dairy products) (RR $0.76,95 \%$ CI $0.60-0.95,3$ studies). High adherence to a Western/unhealthy dietary pattern (high intake of red and processed meat, refined grains, sweets and desserts, and high-fat dairy products) was associated with an increased risk of overall mortality (RR 1.44, 95\% CI 1.17-1.77, 3 studies) [26]. No association was found with single food groups, and no significant results were presented for recurrence or breast cancer-specific mortality [26]. Even though the studies presented as well as the meta-analysis did not find consistent significant effects of dietary patterns and diet quality scores on breast cancer recurrence and breast cancer-specific mortality, it is noteworthy that healthy dietary choices may be important, as women with diagnosed breast cancer are also at risk of death from non-breast cancer-related causes affected by diet. In addition, due to the limited sample sizes and limited observational periods of the current studies, additional cohort as well as intervention studies are needed to investigate the effect of dietary patterns or scores on breast cancer recurrence and mortality.

\section{Mediterranean Diet}

A recent systematic review and meta-analysis included $56 \mathrm{ob-}$ servational studies and examined the effect of the Mediterranean Diet (MedD) on all-cause cancer mortality and cancer-specific mortality in cancer survivors [27]. The highest adherence to a MedD score showed a significant negative correlation with total cancer mortality (RR 0.86, 95\% CI 0.81-0.91, 15 studies) and allcause mortality in breast cancer patients (RR 0.92, 95\% CI $0.87-$ $0.96,16$ studies) [27]. Among cancer survivors, the association between the adherence to the highest MedD category and risk of cancer mortality and recurrence was not significant [27]. Regarding breast cancer, only 1 cohort study investigated the effect of MedD on breast cancer-specific mortality and found no association with the MedD score [22].

However, it may be interesting in this context that adherence to the MedD was found to be associated with a lower incidence rate of breast cancer (RR 0.94, 95\% CI 0.90-0.99, 7 studies) [27]. In addition, the PREDIMED trial examined in a secondary analysis the ef- 
fect of two types of a MedD on the incidence of breast cancer in 4,152 women (without breast cancer history). The MedD group with extra virgin oil showed a significant reduction of breast cancer incidence (HR 0.32, 95\% CI 0.13-0.79), whereas for the MedD group with extra nuts no significant effect was found (HR 0.59, 95\% CI 0.26-1.35) [28]. In summary, despite some evidence for a positive effect of a MedD on breast cancer incidence and all-cause mortality, the few observational studies do not show an association between MedD and breast cancer survival. The ongoing DIANA-5 trial may shed more light on this question [29].

\section{Vegetarian Diet}

It was previously reported that high levels of plasma carotenoids as an expression of a diet high in vegetables and fruit might contribute to a reduction of recurrence or of new primary breast cancer events [30]. A recent systematic review and meta-analysis of observational studies found for vegetarian and vegan diets a significant modest reduction of the incidence risk of total cancer (RR 0.92, 95\% CI 0.87-0.98) but no significant association with allcause mortality and cancer mortality [31]. In general, data on breast cancer are rather scarce.

\section{Low-Carbohydrate Diet}

A prospective study from Japan [32] analyzed the age-adjusted mortality (MBC) from breast cancer (from the Vital Statistics of Japan) as a function of nutrient intake data from the National Nutrition Survey reports. An inverse correlation between the intake of carbohydrates and mortality from breast cancer was found, possibly due to a lower fiber intake associated with a low carbohydrate intake [32]. The Health, Eating, Activity, and Lifestyle (HEAL) study - including 688 pre- and postmenopausal breast cancer survivors (stage 0 -IIIA) - prospectively examined several dietary factors in relation to cancer prognosis. No significant associations were found for carbohydrate intake, glycemic load or glycemic index, and overall mortality as well as breast cancer-specific mortality [33]. Although 'low-carb' und 'ketogenic' diets are popular as well as increasingly promoted and offered to breast cancer survivors, we found no evidence supporting this type of diet, and the Japanese study reported even a negative correlation between carbohydrate intake and breast cancer mortality.

\section{Alcohol}

Observational studies have investigated the relationship between alcohol intake and prognosis in women with breast cancer [34-37]. A recently published systematic review and meta-analysis, including 7 studies for breast cancer, demonstrated that alcohol intake was associated with an increased risk of breast cancer recurrence (RR 1.21, 95\% CI 1.06-1.39). However, an association with overall mortality (including 21 cohort studies with pre- and postdiagnosis alcohol exposure) was not found [26]. Altogether, due to the well-known adverse effects of alcohol on general health as well as its likely contribution to breast cancer development in both preand postmenopausal women [38], adherence to national dietary guidelines for alcohol intake seems to be appropriate also for breast cancer survivors [39]. The German Nutrition Society (DGE) states that alcohol consumption is not recommendable per se but that an alcohol intake of up to $10 \mathrm{~g} /$ day in healthy women and up to $20 \mathrm{~g} /$ day in healthy men is currently considered to be tolerable [40].

Soy

A recent review examined the association between soy intake and breast cancer and concluded that the available data from human studies - concerning risk and prognosis - are too inconsistent for a clear statement [41]. There is limited evidence for a negative correlation of soy/soy products with all-cause mortality in breast cancer patients [18]. In total, there is no general recommendation of a soy-rich nutrition for breast cancer survivors, but occasional intake seems to be acceptable. Supplement intake is clearly not recommended [41].

\section{Vitamin D}

A recent randomized clinical trial examined the effect of combined supplementation with vitamin D and calcium on cancer incidence in 2,303 postmenopausal women and found no significant risk reduction for all cancer types [42]. A comprehensive metaanalysis of the non-skeletal effects of vitamin D supplementation showed a modest reduction of all cancer mortality (RR 0.88, 95\% CI 0.78-0.98) [43]. In addition, higher serum 25-hydroxyvitamin $\mathrm{D}$ levels were found to be associated with lower breast cancer mortality (pooled RR 0.58, 95\% CI 0.40-0.85; highest vs. lowest quintile: HR 0.56, 95\% CI 0.40-0.70) [44]. However, there is no data available on the effect of vitamin D supplementation on breast cancer survival. Various kinds of breast cancer therapy can increase the risk of bone loss; therefore, in women with breast cancer at high risk of fractures, vitamin D supplementation can be considered as a useful preventive measure, particularly in those patients with low 25-hydroxyvitamin D levels.

Alternative and complementary medicine, including dietary supplements, is widely used among breast cancer patients [45-47]. People assume that they can reduce toxic side effects of cancer treatment, prevent cancer recurrence, and improve their overall health $[48,49]$. However, a comprehensive literature review reported mixed results in terms of multivitamin use and breast cancer outcome. Both beneficial and adverse effects on overall and breast-cancer mortality as well as recurrence were observed [11]. The evidence-based S3 guideline 'Clinical Nutrition in Oncology, the German Society for Nutritional Medicine (DGEM)' does not recommend the use of dietary supplements to prevent cancer recurrence in general [50]. The WCRF advises cancer patients to meet nutrient requirements through adequate nutrition without taking supplements [39]. The intake of dietary supplements, especially antioxidants, during radio- and chemotherapy was observed to have undesirable effects in terms of compromising treatment efficacy and protecting tumor cells [51-53]. Based on these observations and the inconsistent data, the DGEM advises cancer patients against the use of supplements (high-dose antioxidants, glutamine, omega-3 fatty acid, fish oil) during chemotherapy treatment [50]. Furthermore, the intake of high or long-term doses of several sup- 
Table 1. Cancer Prevention Recommendations by the World Cancer Research Fund [39]

\section{Keep weight low within the healthy range}

Be physically active for at least 30 min every day, and sit less

Avoid high-calorie foods and sugary drinks

Eat more grains, vegetables, fruit and beans

Limit intake of red meat (less than $500 \mathrm{~g} /$ week) and avoid processed meat

Do not drink alcohol. If you do, limit alcoholic drinks and follow national guidelines

Eat less salt and avoid moldy grains and cereals

Aim to meet nutritional needs through diet alone

plements was found to be associated with the development of specific cancer types [54-56] and can also lead to intoxications [57].

In summary, the use of dietary supplements among cancer patients without confirmed nutritional deficiencies is currently not justified. If their administration is necessary for other medical reasons, it should be regularly monitored by the treating physician.

\section{Dietary Recommendations for Women with Breast Cancer}

A report published by the WCRF in 2014 systematically analyzed the global scientific data on lifestyle factors like diet, physical activity, and body weight in breast cancer survivors [18]. Regarding diet and breast cancer survival, the expert panel concluded that the evidence was:

- limited-suggestive that consumption of foods containing fiber, before and after diagnosis, may decrease all-cause mortality risk;

- limited-suggestive that intake of foods containing soy, after diagnosis, decreased all-cause mortality risk;

- limited-suggestive that a diet high in fat and saturated fat, before diagnosis, increased the risk for all-cause mortality following a breast cancer diagnosis.

Although the panel noted that evidence on survivorship was too limited to make general diet recommendations for breast cancer patients [18], the WCRF suggested that all cancer survivors should follow the general Cancer Prevention Recommendations (table 1) $[39,58]$.

\section{Discussion and Conclusion}

The available data regarding the association between diet or specific dietary components and breast cancer prognosis are limited and often inconsistent. Nevertheless, current data suggest that a healthy diet characterized by a high intake of fruit, vegetables, whole grains, and poultry as well as low-fat dietary products may have a positive effect on breast cancer overall survival, whereas an unhealthy/Western diet including a high intake of red/processed meat, refined grains, sweets/desserts, and high-fat dairy products may result in the opposite. This trend has already been observed earlier and seems to have remained constant during recent years [59].
In terms of breast cancer survival, there is no evidence for any benefit from other special diets like low-carbohydrate, ketogenic or vegetarian diets, despite increasingly promoted in clinical care. A positive effect of the MedD was found for all-cause mortality in breast cancer patients but not for recurrence. A positive effect of the intake of vitamin D on survival from breast cancer is not formally proven by the available data but may be plausible based on studies on breast cancer incidence and total cancer mortality. There is also insufficient evidence for recommendation of a soybased nutrition. Occasional consumption seems to be acceptable, though. For alcohol consumption the results were inconsistent; however, following the recommendations of the WCRF and the national guidelines seems to be reasonable.

Among all lifestyle factors and beyond physical activity the strongest evidence of an impact on breast cancer prognosis was found for obesity and overweight. On average, obesity increases the risk of mortality (all-cause mortality and breast cancer-specific mortality) by approximately $30 \%$ [6]. Based on the fact that women often gain weight after breast cancer diagnosis, which also increases the mortality risk $[60,61]$, not only dietary habits but also body weight control should gain greater attention.

The current knowledge is mainly based on observational studies. Against this background, randomized controlled lifestyle intervention trials are urgently needed to substantiate the observed associations. The two large intervention trials conducted in women with breast cancer so far produced discrepant results and did not provide clear evidence that dietary fat reduction improves prognosis. They also did not consider other important lifestyle factors such as physical activity, body weight control, and diet quality. Thus, clinical trials should investigate multimodal lifestyle interventions including dietary changes and physical activity as well as body weight management. Such multimodal concepts are currently explored in several ongoing lifestyle intervention trials in breast cancer patients. In Germany, the SUCCESS C trial, a multicenter randomized phase III study with a $2 \times 2$ factorial design, currently investigates the effect of an individualized lifestyle intervention aiming at moderate weight loss on disease-free survival in women with Her2/neu-negative breast cancer [62].

Despite the lack of convincing data for a significant effect of nutrition on breast cancer mortality and recurrence, adherence to a healthy diet is also recommended for other reasons. A prudent/ healthy dietary pattern is associated with prevention of and decreased mortality from cardiovascular disease [63, 64], the most common comorbidity of breast cancer survivors [65]. Therefore, changing diet towards a healthy dietary pattern may offer multiple health benefits and improve life expectancy.

\section{Disclosure Statement}

The authors declare that there is no conflict of interest. 


\section{References}

1 Robert Koch-Institut: Bericht zum Krebsgeschehen in Deutschland 2016. 2016. https://www.krebsdaten.de/ Krebs/DE/Content/Publikationen/Krebsgeschehen/ Krebsgeschehen_download.pdf?_blob=publicationFile.

2 Holmes MD, Stampfer MJ, Colditz GA, Rosner B, Hunter DJ, Willett WC: Dietary factors and the survival of women with breast carcinoma. Cancer 1999; 86:826-835.

3 Fink BN, Gaudet MM, Britton JA, Abrahamson PE, Teitelbaum SL, Jacobson J, Bell P, Thomas JA, Kabat GC, Neugut AI, Gammon MD: Fruits, vegetables, and micronutrient intake in relation to breast cancer survival. Breast Cancer Res Treat 2006;98:199-208.

4 McEligot AJ, Largent J, Ziogas A, Peel D, Anton-Culver $\mathrm{H}$ : Dietary fat, fiber, vegetable, and micronutrients are associated with overall survival in postmenopausal women diagnosed with breast cancer. Nutr Cancer 2006;55:132-140.

5 Saxe GA, Rock CL, Wicha MS, Schottenfeld D: Diet and risk for breast cancer recurrence and survival. Breast Cancer Res Treat 1999;53:241-253.

6 Patterson RE, Cadmus LA, Emond JA, Pierce JP: Physical activity, diet, adiposity and female breast cancer prognosis: a review of the epidemiologic literature. Maturitas 2010;66:5-15

7 Chan DSM, Vieira AR, Aune D, Bandera EV, Green wood DC, McTiernan A, Navarro Rosenblatt D, Thune I, Vieira R, Norat T: Body mass index and survival in women with breast cancer-systematic literature review and meta-analysis of 82 follow-up studies. Ann Oncol 2014;25:1901-1914.

8 Kwan ML, Chen WY, Kroenke CH, Weltzien EK, Beasley JM, Nechuta SJ, Poole EM, Lu W, Holmes MD, Quesenberry CP, Pierce JP, Shu XO, Caan BJ: Pre-diagnosis body mass index and survival after breast cancer in the After Breast Cancer Pooling Project. Breast Cancer Res Treat 2012;132:729-739.

9 Chen X, Lu W, Zheng W, Gu K, Chen Z, Zheng Y, Shu $\mathrm{XO}$ : Obesity and weight change in relation to breast cancer survival. Breast Cancer Res Treat 2010;122:823-833.

10 Ibrahim EM, Al-Homaidh A: Physical activity and survival after breast cancer diagnosis: meta-analysis of published studies. Med Oncol 2011;28:753-765.

11 Chlebowski RT: Nutrition and physical activity influence on breast cancer incidence and outcome. Breast 2013;22(suppl 2):S30-37.

12 Dieli-Conwright CM, Lee K, Kiwata JL: Reducing the risk of breast cancer recurrence: an evaluation of the effects and mechanisms of diet and exercise. Curr Breast Cancer Rep 2016;8:139-150.

13 Holmes MD, Chen WY, Feskanich D, Kroenke CH, Colditz GA: Physical activity and survival after breast cancer diagnosis. JAMA 2005;293:2479-2486.

14 Passarelli MN, Newcomb PA, Hampton JM, TrenthamDietz A, Titus LJ, Egan KM, Baron JA, Willett WC Cigarette smoking before and after breast cancer diagnosis: mortality from breast cancer and smoking-related diseases. J Clin Oncol 2016;34:1315-1322.

15 Pierce JP, Patterson RE, Senger CM, Flatt SW, Caan BJ Natarajan L, Nechuta SJ, Poole EM, Shu X-O, Chen WY: Lifetime cigarette smoking and breast cancer prognosis in the After Breast Cancer Pooling Project. J Natl Cancer Inst 2014;106:djt359.

16 Kwan ML, Bernard PS, Kroenke CH, Factor RE, Habel LA, Weltzien EK, Castillo A, Gunderson EP, Maxfield KS, Stijleman IJ, Langholz BM, Quesenberry CP, Kushi LH, Sweeney C, Caan BJ: Breastfeeding, PAM50 tumor subtype, and breast cancer prognosis and survival. J Natl Cancer Inst 2015;107:pii: djv087.

17 Hauner D, Janni W, Rack B, Hauner H: The effect of overweight and nutrition on prognosis in breast cancer. Dtsch Arztebl Int 2011;108:795-801.
18 World Cancer Research Fund International: Continuous Update Project Report: Diet, Nutrition, Physical Activity, and Breast Cancer Survivors. 2014. www. wcrf.org/sites/default/files/Breast-Cancer-Survivors2014-Report.pdf.

19 Chlebowski RT, Blackburn GL, Thomson CA, et al: Dietary fat reduction and breast cancer outcome: interim efficacy results from the Women's Intervention Nutrition Study. J Natl Cancer Inst 2006;98:1767-1776.

20 Pierce JP, Natarajan L, Caan BJ, et al: Influence of a diet very high in vegetables, fruit, and fiber and low in fat on prognosis following treatment for breast cancer: the Women's Healthy Eating and Living (WHEL) randomized trial. JAMA 2007;298:289-298.

21 Kroenke CH, Fung TT, Hu FB, Holmes MD: Dietary patterns and survival after breast cancer diagnosis. J Clin Oncol 2005;23:9295-9303.

22 Kim EHJ, Willett WC, Fung T, Rosner B, Holmes MD: Diet quality indices and postmenopausal breast cancer survival. Nutr Cancer 2011;63:381-388.

23 Kwan ML, Weltzien E, Kushi LH, Castillo A, Slattery ML, Caan BJ: Dietary patterns and breast cancer recurrence and survival among women with early-stage breast cancer. J Clin Oncol 2009;27:919-926.

24 Izano MA, Fung TT, Chiuve SS, Hu FB, Holmes MD: Are diet quality scores after breast cancer diagnosis associated with improved breast cancer survival? Nutr Cancer 2013;65:820-826

25 Vrieling A, Buck K, Seibold P, Heinz J, Obi N, FleschJanys D, Chang-Claude J: Dietary patterns and survival in German postmenopausal breast cancer survivors. $\mathrm{Br}$ J Cancer 2013;108:188-192.

26 Schwedhelm C, Boeing H, Hoffmann G, Aleksandrova $\mathrm{K}$, Schwingshackl L: Effect of diet on mortality and cancer recurrence among cancer survivors: a systematic review and meta-analysis of cohort studies. Nutr Rev 2016;74:737-748.

27 Schwingshackl L, Schwedhelm C, Galbete C, Hoffmann G: Adherence to Mediterranean Diet and risk of cancer: an updated systematic review and meta-analysis. Nutrients 2017;9:pii: E1063.

28 Toledo E, Salas-Salvadó J, Donat-Vargas C, et al: Mediterranean diet and invasive breast cancer risk among women at high cardiovascular Risk in the PREDIMED trial: a randomized clinical trial. JAMA Intern Med 2015;175:1752-1760.

29 Villarini A, Pasanisi P, Traina A, et al: Lifestyle and breast cancer recurrences: the DIANA- 5 trial. Tumori 2012;98:1-18.

30 Rock CL, Natarajan L, Pu M, Thomson CA, Flatt SW, Caan BJ, Gold EB, Al-Delaimy WK, Newman VA, Hajek RA, Stefanick ML, Pierce JP: Longitudinal biological exposure to carotenoids is associated with breast cancer-free survival in the Women's Healthy Eating and Living Study. Cancer Epidemiol Biomarkers Prev 2009; 18:486-494.

31 Dinu M, Abbate R, Gensini GF, Casini A, Sofi F: Vegetarian, vegan diets and multiple health outcomes: a systematic review with meta-analysis of observational studies. Crit Rev Food Sci Nutr 2017;57:3640-3649.

32 Harashima E, Nakagawa Y, Urata D, Tsuji K, Shirataka M, Matsumura Y: Time-lag estimate between dietary intake and breast cancer mortality in Japan. Asia Pac J Clin Nutr 2007;16:193-198.

33 Belle FN, Kampman E, McTiernan A, Bernstein L, Baumgartner K, Baumgartner R, Ambs A, BallardBarbash R, Neuhouser ML: Dietary fiber, carbohydrates, glycemic index, and glycemic load in relation to breast cancer prognosis in the HEAL cohort. Cancer Epidemiol Biomarkers Prev 2011;20:890-899.
34 Kwan ML, Kushi LH, Weltzien E, Tam EK, Castillo A Sweeney C, Caan BJ: Alcohol consumption and breast cancer recurrence and survival among women with early-stage breast cancer: the life after cancer epidemiology study. J Clin Oncol 2010;28:4410-4416.

35 Kwan ML, Chen WY, Flatt SW, Weltzien EK, Nechuta SJ, Poole EM, Holmes MD, Patterson RE, Shu XO, Pierce JP, Caan BJ: Postdiagnosis alcohol consumption and breast cancer prognosis in the after breast cancer pooling project. Cancer Epidemiol Biomarkers Prev 2013;22:32-41.

36 Nechuta S, Chen WY, Cai H, Poole EM, Kwan ML, Flatt SW, Patterson RE, Pierce JP, Caan BJ, Ou Shu X: A pooled analysis of post-diagnosis lifestyle factors in association with late estrogen-receptor-positive breast cancer prognosis. Int J Cancer 2016;138:2088-2097.

37 Ali AMG, Schmidt MK, Bolla MK, et al: Alcohol consumption and survival after a breast cancer diagnosis: a literature-based meta-analysis and collaborative analysis of data for 29,239 cases. Cancer Epidemiol Biomarkers Prev 2014;23:934-945.

38 World Cancer Research Fund International/American Institute for Cancer Research: Continuous Update Project Report: Diet, Nutrition, Physical Activity and Breast Cancer. 2017. www.wcrf.org/sites/default/files/ CUP_BREAST_REPORT_2017_WEB.pdf.

39 World Cancer Research Fund International: Our Cancer Prevention Recommendations, 2018. www. wcrf.org/int/research-we-fund/our-cancer-preventionrecommendations (accessed January 30, 2018).

40 Deutsche Gesellschaft für Ernährung e.V.: Alkohol Richtwert für Alkohol. www.dge.de/wissenschaft/referenzwertelalkohol/ (accessed January 30, 2018).

41 Hauner D: Soja and Mammakarzinom: Wirkung und Sicherheit zur Primärprävention und bei bereits Erkrankten. Gynäkologische Praxis 2017;42:683-691.

42 Lappe J, Watson P, Travers-Gustafson D, Recker R, Garland C, Gorham E, Baggerly K, McDonnell SL: Effect of vitamin $\mathrm{D}$ and calcium supplementation on cancer incidence in older women: a randomized clinical trial. JAMA 2017;317:1234-1243.

43 Autier P, Mullie P, Macacu A, Dragomir M, Boniol M, Coppens K, Pizot C, Boniol M: Effect of vitamin D supplementation on non-skeletal disorders: a systematic review of meta-analyses and randomised trials. Lancet Diabetes Endocrinol 2017;5:986-1004.

44 Hamer J, Warner E: Lifestyle modifications for patients with breast cancer to improve prognosis and optimize overall health. CMAJ 2017;189:E268-E274.

45 Velicer CM, Ulrich CM: Vitamin and mineral supplement use among US adults after cancer diagnosis: a systematic review. J Clin Oncol 2008;26:665-673.

46 Horneber M, Bueschel G, Dennert G, Less D, Ritter E Zwahlen M: How many cancer patients use complementary and alternative medicine: a systematic review and metaanalysis. Integr Cancer Ther 2012;11:187-203.

47 Nahleh Z, Tabbara IA: Complementary and alternative medicine in breast cancer patients. PAX 2003;1:136.

48 Huebner J, Marienfeld S, Abbenhardt C, Ulrich CM, Muenstedt K, Micke O, Muecke R, Loeser C: Counseling patients on cancer diets: a review of the literature and recommendations for clinical practice. Anticancer Res 2014;34:39-48.

49 Greenlee H, Gammon MD, Abrahamson PE, Gaudet MM, Terry MB, Hershman DL, Desai M, Teitelbaum SL, Neugut AI, Jacobson JS: Prevalence and predictors of antioxidant supplement use during breast cancer treatment: the Long Island Breast Cancer Study Project. Cancer 2009;115:3271-3282. 
50 Arends J, Bertz H, Bischoff S, Fietkau R, Herrmann H, Holm E, Horneber M, Hütterer E, Körber J, Schmid I: S3-Leitline der Deutschen Gesellschaft für Ernährungsmedizin e.V. (DGEM) in Kooperation mit der Deutschen Gesellschaft für Hämatologie und Onkologie e.V. (DGHO), der Arbeitsgemeinschaft 'Supportive Maßnahmen in der Onkologie, Rehabilitation und Sozialmedizin' der Deutschen Krebsgesellschaft (ASORS) und der Österreichischen Arbeitsgemeinschaft für klinische Ernährung (AKE). Aktuel Ernahrungsmed 2015;40:e1-e74.

51 Lawenda BD, Kelly KM, Ladas EJ, Sagar SM, Vickers A, Blumberg JB: Should supplemental antioxidant administration be avoided during chemotherapy and radiation therapy? J Natl Cancer Inst 2008; 100:773-783.

52 Golden EB, Lam PY, Kardosh A, Gaffney KJ, Cadenas E, Louie SG, Petasis NA, Chen TC, Schönthal AH: Green tea polyphenols block the anticancer effects of bortezomib and other boronic acid-based proteasome inhibitors. Blood 2009;113:5927-5937.

53 Bairati I, Meyer F, Gélinas M, Fortin A, Nabid A, Brochet F, Mercier J-P, Têtu B, Harel F, Abdous B, Vigneault E, Vass S, Del Vecchio P, Roy J: Randomized trial of antioxidant vitamins to prevent acute adverse effects of radiation therapy in head and neck cancer patients. J Clin Oncol 2005;23:5805-5813.
54 Tanvetyanon T, Bepler G: Beta-carotene in multivitamins and the possible risk of lung cancer among smokers versus former smokers. Cancer 2008;113:150-157.

55 Brasky TM, White E, Chen C-L: Long-term, supplemental, one-carbon metabolism-related vitamin B use in relation to lung cancer risk in the Vitamins and Lifestyle (VITAL) cohort. J Clin Oncol 2017;35:3440-3448.

56 Wien TN, Pike E, Wisløff T, Staff A, Smeland S, Klemp M: Cancer risk with folic acid supplements: a systematic review and meta-analysis. BMJ Open 2012;2: e000653.

57 Rutkowski M, Grzegorczyk K: Adverse effects of antioxidative vitamins. Int J Occup Med Environ Health 2012;25:105-121.

58 World Cancer Research Fund International: Cancer survivors. www.wcrf.org/int/research-we-fund/cancerprevention-recommendations/cancer-survivors (accessed January 25,2018 ).

59 Hauner H, Hauner D: The impact of nutrition on the development and prognosis of breast cancer. Breast Care (Basel) 2010;5:377-381.

60 Irwin ML, McTiernan A, Baumgartner RN, Baumgartner KB, Bernstein L, Gilliland FD, Ballard-Barbash $\mathrm{R}$ : Changes in body fat and weight after a breast cancer diagnosis: influence of demographic, prognostic, and lifestyle factors. J Clin Oncol 2005;23:774-782.
61 Vance V, Mourtzakis M, McCargar L, Hanning R: Weight gain in breast cancer survivors: prevalence, pattern and health consequences. Obes Rev 2011;12: 282-294.

62 Rack B, Andergassen U, Neugebauer J, Salmen J, Hepp P, Sommer H, Lichtenegger W, Friese K, Beckmann MW, Hauner D, Hauner H, Janni W: The German SUCCESS C study - the first european lifestyle study on breast cancer. Breast Care (Basel) 2010;5:395-400.

63 Fung TT, Rexrode KM, Mantzoros CS, Manson JE, Willett WC, Hu FB: Mediterranean diet and incidence of and mortality from coronary heart disease and stroke in women. Circulation 2009;119:1093-1100.

64 Heidemann C, Schulze MB, Franco OH, van Dam RM, Mantzoros CS, Hu FB: Dietary patterns and risk of mortality from cardiovascular disease, cancer, and all causes in a prospective cohort of women. Circulation 2008;118:230-237.

65 Patnaik JL, Byers T, DiGuiseppi C, Dabelea D, Denberg TD: Cardiovascular disease competes with breast cancer as the leading cause of death for older females diagnosed with breast cancer: a retrospective cohort study. Breast Cancer Res 2011;13:R64. 